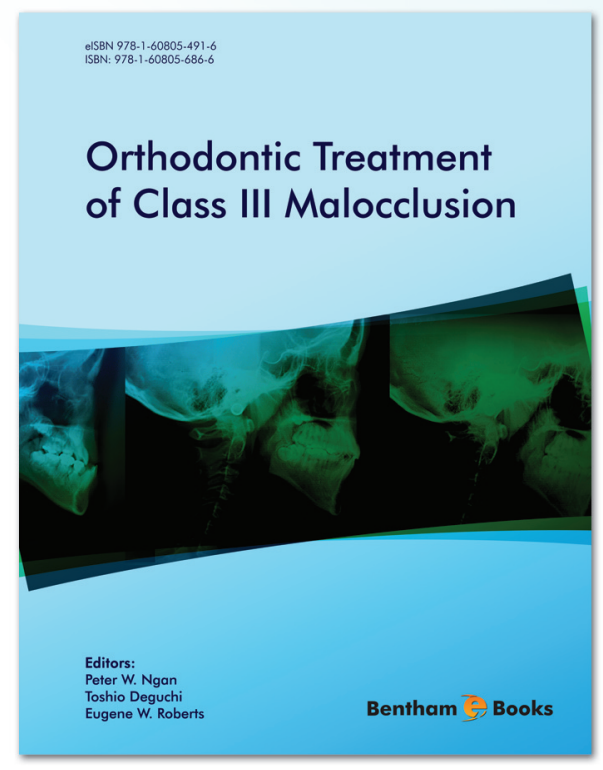

Editors:

\title{
Orthodontic Treatment of Class III Malocclusion
}

\section{wwr.ehooks.hentheamseience.com/hook/9781608054916}

\section{About the eBook}

This eBook is a clinical textbook which highlights both research findings as well as clinical treatment of patients with Class III malocclusions. The contents of this volume will empower clinicians with sound knowledge about rationale for using certain treatment modalities and will help both general practitioners and specialists such as pediatric dentists and orthodontists to use this information for their daily practice.

\section{Contents}

- Family History and Genetics of Mandibular Prognathism

- Class III Skeletal Growth Pattern

- Mechano-Reaction of Chondrocytes in the Mandibular Condyle During Orthopedic-Orthodontic Intervention

- Treatment of Class III Malocclusions in the Growing Patients

- Class III Orthopedic Treatment with Skeletal Anchorage

- Stability of Class III Treatment Strategies in Growing Patients: A Systematic Review of the Literature

- Anterior Crossbite Treatment with a Self-Ligating Bracket System

- Treatment of Class III Cases with Temporary Anchorage Devices For Sales Advertising Inquiries: Contact: marketing@benthamscience.org 